\title{
Experimental and numerical investigations on projectile penetration into polypropylene fiber reinforced concrete targets
}

\author{
Q. Fang, X. F. Hou, Y. N. Zhang \& Y. D. Zhang \\ Department of Civil Engineering, Nanjing Engineering Institute, China
}

\begin{abstract}
Dynamic tests were performed on 64 polypropylene fiber reinforced concrete (PFRC) specimens by the Split Hopkinson Pressure Bar (SHPB) with the diameter of $74 \mathrm{~mm}$. The dynamic stress-strain curves at the strain rate between $10 \mathrm{~s}^{-1}$ and $10^{2} \mathrm{~s}^{-1}$ were obtained. The effects of the strain rate, fiber volume content and static strength on dynamic compression strength were analyzed. The penetration of the armor piercing (AP) projectile into the PFRC targets was investigated experimentally, and simulated by the LS-DYNA. The parameters of the Johnson-Homquist-Concrete (JHC) model were obtained by the SHPB test data and other relevant experimental data. A good agreement between the numerical predictions for the penetration depth and experimental data is observed.

Keywords: polypropylene fiber reinforced concrete, SHPB, strain rate, penetration, numerical simulation, LS-DYNA.
\end{abstract}

\section{Introduction}

It is well known that the addition of small amount of polypropylene fibers into concrete can enhance the tensile and fatigue resistance and toughness of concrete. Although the mechanical properties of PFRC have been investigated intensively, and widely used in engineering, most of these investigations and applications were only limited to the static case and low fiber volume contents $(0.05 \sim 0.3 \%)[1-4]$.

In this paper, the dynamic properties of PFRC with high fiber volume content were studied experimentally by the SHPB with diameter of $74 \mathrm{~mm}$. The strain rate was in the range of $10^{1} \mathrm{~s}^{-1}$ to $10^{2} \mathrm{~s}^{-1}$. The penetration of the $37 \mathrm{~mm} \mathrm{AP}$ 
projectile into the PFRC targets was tested. The parameters of the Johnson-Homquist-Concrete (JHC) model were obtained by the SHPB test data and other relevant experimental data. And the penetration tests were simulated numerically by the LS-DYNA.

\section{SHPB test}

\subsection{Test equipment and specimens}

The test equipment is a large-size Hopkinson pressure bar with variable cross-sections. The strike bar and the pressure bar are made of alloy steel. The diameter of the cross-section of the strike bar and small end of the input pulse bar is $37 \mathrm{~mm}$, and the diameter of the cross-section of the large end of the input pulse bar and the output pulse bar is $74 \mathrm{~mm}$. To improve the precision of SHPB test, latten is used at the small end of the input bar. It can elongate the rising time of the incident wave and improve the wave pattern effectively.

The general size of the coarse aggregate in PFRC specimens was smaller than usual experiments in order to reduce the size effect. There were 64 PFRC specimens, classified into 8 groups based on the different fiber volume content $\left(\rho_{f}\right)$ and static compressive strength $\left(\sigma_{\mathrm{s}}\right)$. Table 1 gives static strength and fiber volume content of specimens. The diameter of PFRC specimens was $72 \mathrm{~mm}$ and the thickness was $33 \mathrm{~mm}$

Table 1: $\quad$ Static strength and fiber volume content of specimens.

\begin{tabular}{|c|c|c|c|c|c|c|c|c|}
\hline $\begin{array}{c}\text { Specimen } \\
\text { group }\end{array}$ & PF1 & PF2 & PF3 & PF4 & PF5 & PF6 & PF7 & PF8 \\
\hline$\sigma_{\mathrm{s}}(\mathrm{MPa})$ & 24 & 25 & 45 & 46 & 55 & 55 & 55 & 56 \\
\hline$\rho_{f}(\%)$ & 0 & 1 & 1 & 2 & 1 & 1.5 & 1 & 0 \\
\hline
\end{tabular}

\subsection{Results and discussion}

The SHPB test was conducted under $0.6 \mathrm{MPa}$ and 1.0 $\mathrm{MPa}$ impact pressure respectively, and dynamic stress-strain curve of each specimen was got. To decrease the error induced by data dispersancy, the average value of the dynamic stress-strain curves of each specimen group was adopted based on the same impact air pressure. The experimental results of PF3 and PF5 are only presented in Table 2, Table 3 and Figure 1, due to the limitation of space.

In Table 2, Table 3 and Figure 1, $P$ is the impact pressure, $\dot{\varepsilon}$ is the strain rate, $\overline{\dot{\varepsilon}}$ is the average strain rate, $\sigma_{d}$ is the average dynamic compressive strength. $\sigma_{d} / \sigma_{\mathrm{s}}$ denotes the ratio of dynamic compressive strength to static compressive strength.

The curves in Figure 1 show that the elastic modulus keeps unchanged with the rising of strain rate. The results in Table 2 and Table 3 show that $\sigma_{d} / \sigma_{\mathrm{s}}$ increases with the increasing of $\dot{\varepsilon}$. 


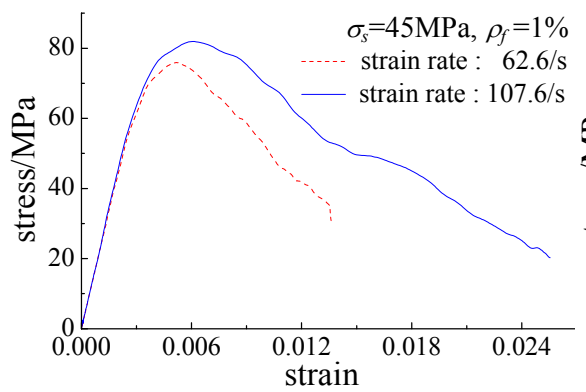

(a) specimen PF3

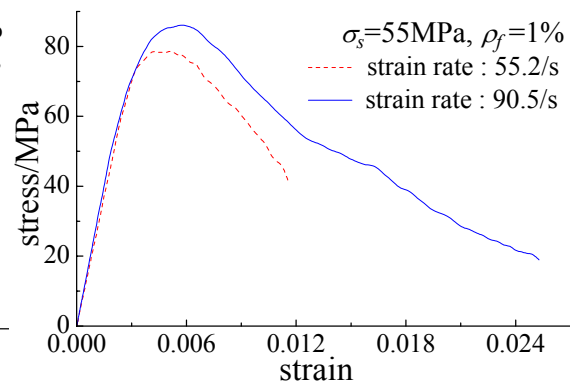

(b) specimen PF5

Figure 1: Dynamic strain-stress curves.

Table 2: $\quad$ Test results of specimen PF3.

\begin{tabular}{|c|c|c|c|c|c|c|}
\hline $\begin{array}{c}\sigma_{\mathrm{s}} \\
(\mathrm{MPa})\end{array}$ & $\begin{array}{c}\rho_{f} \\
(\%)\end{array}$ & $\begin{array}{c}P \\
(\mathrm{MPa})\end{array}$ & $\begin{array}{c}\dot{\varepsilon} \\
\left(\mathrm{s}^{-1}\right)\end{array}$ & $\begin{array}{c}\overline{\bar{\varepsilon}} \\
\left(\mathrm{s}^{-1}\right)\end{array}$ & $\begin{array}{c}\sigma_{d} \\
(\mathrm{MPa})\end{array}$ & $\sigma_{d} / \sigma_{\mathrm{s}}$ \\
\hline \multirow{9}{*}{45} & \multirow{9}{*}{1} & \multirow{4}{*}{0.6} & 61 & \multirow{4}{*}{63} & \multirow{4}{*}{76} & 1.73 \\
\hline & & & 59 & & & 1.62 \\
\hline & & & 64 & & & 1.78 \\
\hline & & & 67 & & & 1.56 \\
\hline & & \multirow{5}{*}{1.0} & 87 & \multirow{5}{*}{108} & \multirow{5}{*}{82} & 1.84 \\
\hline & & & 95 & & & 1.78 \\
\hline & & & 111 & & & 1.96 \\
\hline & & & 119 & & & 1.80 \\
\hline & & & 127 & & & 1.87 \\
\hline
\end{tabular}

Table 3: $\quad$ Test results of specimen PF5.

\begin{tabular}{|c|c|c|c|c|c|c|}
\hline $\begin{array}{c}\sigma_{\mathrm{s}} \\
(\mathrm{MPa})\end{array}$ & $\begin{array}{c}\rho_{f} \\
(\%)\end{array}$ & $\begin{array}{c}P \\
(\mathrm{MPa}) \\
\end{array}$ & $\begin{array}{c}\dot{\varepsilon} \\
\left(\mathrm{s}^{-1}\right)\end{array}$ & $\begin{array}{c}\overline{\dot{\varepsilon}} \\
\left(\mathrm{s}^{-1}\right)\end{array}$ & $\begin{array}{c}\sigma_{d} \\
(\mathrm{MPa})\end{array}$ & $\sigma_{d} / \sigma_{\mathrm{s}}$ \\
\hline \multirow{8}{*}{55} & \multirow{8}{*}{1} & \multirow{3}{*}{0.6} & 45 & \multirow{3}{*}{44} & \multirow{3}{*}{104} & 1.78 \\
\hline & & & 49 & & & 1.87 \\
\hline & & & 38 & & & 2.00 \\
\hline & & \multirow{5}{*}{1.0} & 64 & \multirow{5}{*}{66} & \multirow{5}{*}{120} & 2.29 \\
\hline & & & 73 & & & 1.96 \\
\hline & & & 62 & & & 2.33 \\
\hline & & & 66 & & & 2.27 \\
\hline & & & 65 & & & 2.13 \\
\hline
\end{tabular}




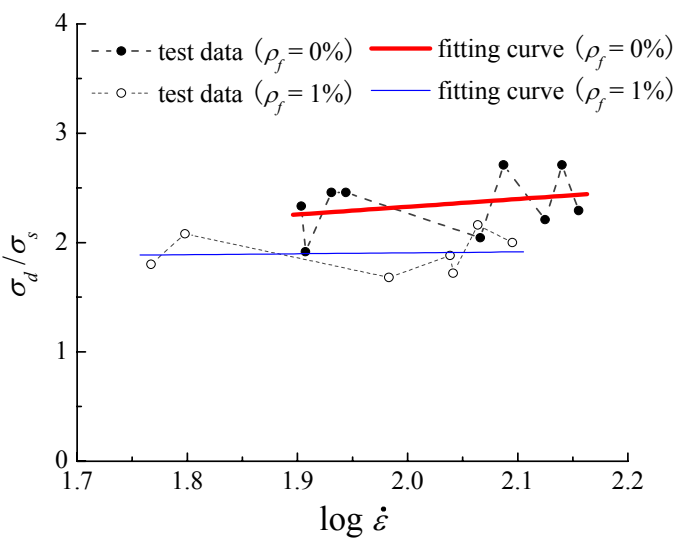

(a) $\sigma_{\mathrm{s}}=25 \mathrm{MPa}$

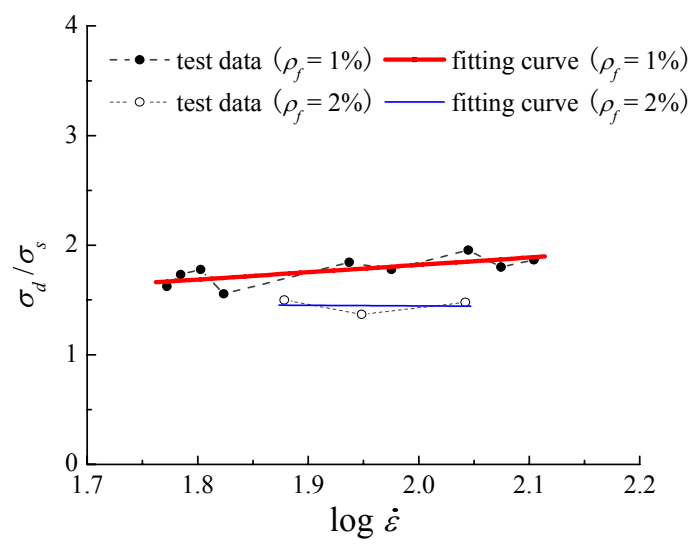

(b) $\sigma_{\mathrm{s}}=45 \mathrm{MPa}$

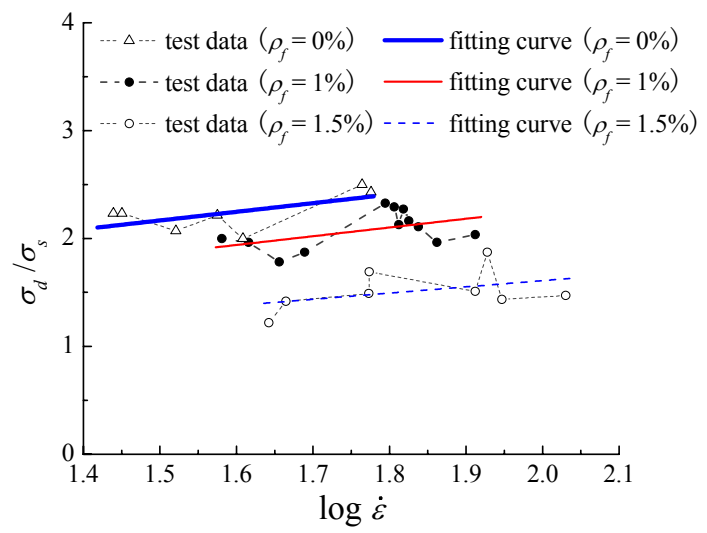

(c) $\sigma_{\mathrm{s}}=55 \mathrm{MPa}$

Figure 2: $\quad$ Relationship between $\sigma_{d} / \sigma_{\mathrm{s}}$ and $\lg \dot{\varepsilon}$. 
The relationship between $\sigma_{d} / \sigma_{\mathrm{s}}$ and $\lg \dot{\varepsilon}$ is shown in Figure 2. The average values of $\sigma_{d} / \sigma_{\mathrm{s}}$, denoted by $\overline{\sigma_{d} / \sigma_{s}}$, of each specimen group are given in Table 4. The results in Figure 2 and Table 4 show that $\sigma_{d} / \sigma_{\mathrm{s}}$ decreases as $\rho f$ increase when $\dot{\varepsilon}$ and $\sigma_{\mathrm{s}}$ kept unchanged. For example, in the case of $\sigma_{\mathrm{s}}=55$ $\mathrm{MPa}$ and $\dot{\varepsilon}=1.7, \sigma_{d} / \sigma_{\mathrm{s}}$ reduces from 2.4 to 1.4 when $\rho_{f}$ increases from $0 \%$ to $1.5 \%$. It is indicated that the addition of excessive fiber has a negative effect on the dynamic compressive strength of PFRC. Bischoff gave experimental data about the relationships between $\sigma_{d} / \sigma_{\mathrm{s}}$ and $\lg \dot{\varepsilon}$ of plain concrete [5-7]. Figure 3 shows both concrete test data given by Bischoff and PFRC test data by the author. It is shown that PFRC has the same rate sensitivity with concrete.

Table 4: The average values of $\sigma_{d} / \sigma_{\mathrm{s}}$ of the specimens.

\begin{tabular}{|c|c|c|c|c|c|c|c|c|}
\hline Specimen group & PF1 & PF2 & PF3 & PF4 & PF5 & PF6 & PF7 & PF8 \\
\hline$\sigma_{\mathrm{s}}(\mathrm{MPa})$ & 24 & 25 & 45 & 46 & 55 & 55 & 55 & 56 \\
\hline$\rho_{f}(\%)$ & 0 & 1 & 1 & 2 & 1 & 1.5 & 1 & 0 \\
\hline$\overline{\sigma_{d} / \sigma_{s}}$ & 2.35 & 1.90 & 1.78 & 1.45 & 2.0 & 1.51 & 2.05 & 2.30 \\
\hline
\end{tabular}

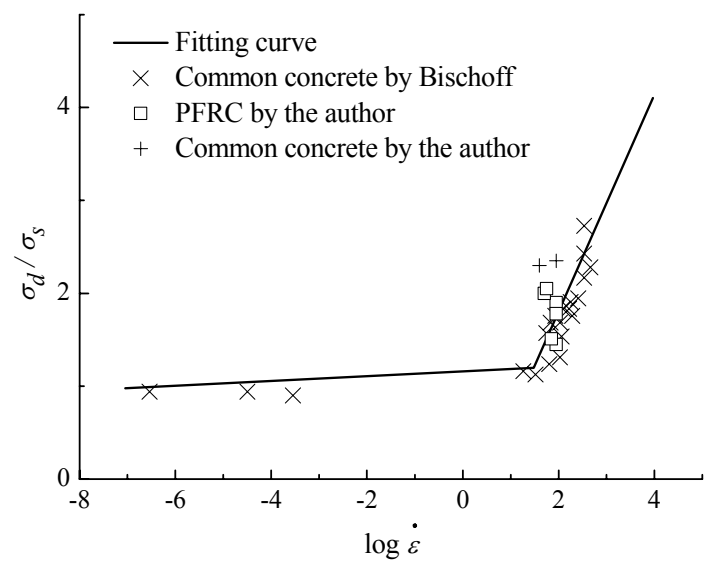

Figure 3: Relationship between $\sigma_{d} / \sigma_{\mathrm{s}}$ and $\lg \dot{\varepsilon}$ of concrete and PFRC.

\section{Penetration test}

The penetration of the $37 \mathrm{~mm}$ AP projectile, shown in Figure 4, into PFRC targets with different fiber volume content were studied experimentally. The size of PFRC target was $1000 \mathrm{~mm}$ in diameter and $200 \mathrm{~mm}$ in thickness, a steel plate with $3 \mathrm{~mm}$ thick was adhere to the back of the target and $2 \mathrm{~m}$ thick soil bags piled up at the back of the steel plate. The relevant parameters and results of penetration tests are listed in Table 5. 


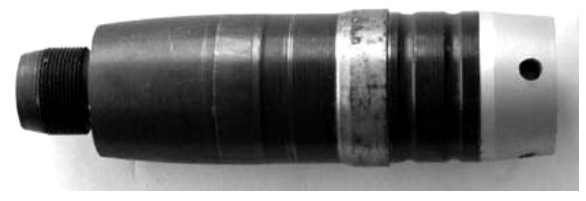

Figure 4: $\quad 37 \mathrm{~mm} \mathrm{AP.}$

Table 5: $\quad$ Penetration test results.

\begin{tabular}{|c|c|c|c|c|c|c|}
\hline \multirow{2}{*}{ Specimen } & \multirow{2}{*}{$\begin{array}{c}\rho_{f} \\
(\%)\end{array}$} & \multirow{2}{*}{$\begin{array}{c}\sigma_{\mathrm{s}} \\
(\mathrm{MPa})\end{array}$} & \multirow{2}{*}{$\begin{array}{l}\text { Weight of } \\
\text { projectile } \\
(\mathrm{g})\end{array}$} & \multirow{2}{*}{$\begin{array}{c}\text { Velocity of } \\
\text { projectile }(\mathrm{m} / \mathrm{s})\end{array} \mid$} & \multicolumn{2}{|c|}{ Penetration depth $(\mathrm{cm})$} \\
\hline & & & & & Test & Numerical \\
\hline PFP1 & 0 & 74.8 & 694 & 671 & 20.0 & 21.9 \\
\hline PFP2 & \multirow{2}{*}{0.2} & \multirow{2}{*}{88.2} & 695 & 436 & 13.0 & 12.7 \\
\hline PFP3 & & & 694 & 509 & 16.0 & 16.4 \\
\hline PFP4 & \multirow{2}{*}{0.3} & \multirow{2}{*}{88.0} & 697 & 419 & 10.3 & 11.9 \\
\hline PFP5 & & & 695 & 501 & 21.0 & 15.2 \\
\hline
\end{tabular}

\section{Numerical analysis}

The penetration tests were simulated by the LS-DYNA dynamic finite element analysis software. The projectile is made of $35 \mathrm{CrMnSi}$ alloy steel, it was hardly deformed in the test and can be simulated by the rigid body. The steel plate was simulated by elastoplastic model, and soil by elastic model. The relevant parameters are given in Table 6.

Table 6: The model parameters of the projectile, soil and steel plate (unit in cm-g- $\mu \mathrm{s}-\mathrm{K})$.

\begin{tabular}{|c|c|c|c|c|c|c|}
\hline Material & Density & $\begin{array}{c}\text { Yong's } \\
\text { modulus }\end{array}$ & $\begin{array}{c}\text { Poisson's } \\
\text { ratio }\end{array}$ & $\begin{array}{c}\text { Yield } \\
\text { strength }\end{array}$ & $\begin{array}{c}\text { Hardening } \\
\text { modulus }\end{array}$ & $\begin{array}{c}\text { Hardening } \\
\text { parameter }\end{array}$ \\
\hline Projectile & 5.88 & 2.1 & 0.2 & - & - & - \\
\hline Soil & 1.55 & $4.0 \times 10^{-5}$ & 0.2 & - & - & - \\
\hline Steel plate & 7.8 & 2.1 & 0.2 & $3.1 \times 10^{-3}$ & 0.21 & 1.0 \\
\hline
\end{tabular}

The PFRC target was simulated by JHC model [8, 9], which is a widely-used constitutive model for concrete subjected to large strain, high strain rate, and high pressure. The influence of polypropylene fibers was considered when determining the model parameters. The equivalent strength is expressed as a function of the pressure, strain rate, and damage. The pressure is expressed as a function of the volumetric strain and includes the effect of permanent crushing. 
The damage is accumulated as a function of the plastic volumetric strain, equivalent plastic strain, and pressure.

The normalized equivalent stress is defined as $\sigma^{*}=\sigma / f_{c}^{\prime}$, where $\sigma$ is the actual equivalent stress and $f_{c}^{\prime}$ is the quasi-static uniaxial compressive strength. The expression of the normalized equivalent stress $\sigma^{*}$ is given as follows [9]

$$
\sigma^{*}=\left[A(1-D)+B p^{* N}\right]\left[1+C \ln \dot{\varepsilon}^{*}\right] \leq S_{\max }
$$

where $D$ is the damage parameter $(0 \leq D \leq 1), C$ is the material coefficient relevant to strain rate, and $A$ and $B$ are material constant relevant to elastoplastic deformation.

The JHC model accumulates damage from both equivalent plastic strain and plastic volumetric strain, and damage parameter is expressed as

$$
D=\sum \frac{\Delta \varepsilon_{p}+\Delta \mu_{p}}{\varepsilon_{p}^{f}+\mu_{p}^{f}}
$$

where $\Delta \varepsilon_{p}$ and $\Delta \mu_{p}$ are the equivalent plastic strain and plastic volumetric strain respectively during a cycle of integration, and $\varepsilon_{p}^{f}+\mu_{p}^{f}=f(p)$ is the plastic strain at the fracture under a constant pressure $p$, expressed by

$$
\varepsilon_{p}^{f}+\mu_{p}^{f}=f(p)=D_{1}\left(p^{*}+T^{*}\right)^{D_{2}}
$$

where $D_{1}$ and $D_{2}$ are constants, $p^{*}=p / f_{c}^{\prime}$ and $T^{*}=T / f_{c}^{\prime}$. The detail description of the JHC model can be found in reference [9].

The relationship between plastic strain and plastic volumetric strain under the uniaxial stress state is expressed as

$$
\mu_{p}^{f}=(1+2 \mu)\left(\varepsilon^{f}-\varepsilon^{e}\right)=(1+2 \mu) \varepsilon_{p}^{f}
$$

$p^{*}=1 / 2$ and $\varepsilon_{p}^{f}=0.014$ may be given by the SHPB test data. Therefore, $D_{1}$ can be expressed as follows from the equation (3) and equation (4)

$$
D_{1}=\frac{2(1+\mu) \varepsilon_{p}^{f}}{\left(p^{*}+T^{*}\right)^{D_{2}}}
$$

$D_{2}=1.0, T^{*}=0.083$ and $\mu=0.2$ can be given by Bischoff's test data [7]. Hence, the value of $D_{1}$ can be got as $D_{1}=0.058$. The other parameters of PFRC are taken the same with concrete. Taking target PFP4 for example, the model parameters of PFRC are given in Table 7. The detail expressions of these parameters can be found in LS-DYNA keyword user's manual [10].

In addition, the material constant relevant to strain rate $C$ can be determined by Figure 3, the result is $C=0.007$.

Figure 5 show the analytical model and discretizated by axial symmetry element. The number of the element for the projectile, target, steel plate and soil bags are 214, 23798, 354 and 62604, respectively. 
Table 7: $\quad$ The JHC model parameters of PFRC (unit: $\mathrm{cm}-\mathrm{g}-\mu \mathrm{s}-\mathrm{K}$ ).

\begin{tabular}{|c|c|c|c|}
\hline Parameter & Value & Parameter & Value \\
\hline$R O$ & 2.44 & $S F M A X$ & 7.0 \\
\hline$G$ & 0.176 & $P C$ & $2.667 \times 10^{-4}$ \\
\hline$A$ & 0.79 & $U C$ & $1.34 \times 10^{-3}$ \\
\hline$B$ & 1.60 & $P L$ & $1.05 \times 10^{-2}$ \\
\hline$C$ & 0.007 & $U L$ & 0.1 \\
\hline$N$ & 0.61 & $D_{1}$ & 0.058 \\
\hline$F C$ & $8.0 \times 10^{-4}$ & $D_{2}$ & 1.0 \\
\hline$T$ & $5.0 \times 10^{-5}$ & $K_{1}$ & 0.174 \\
\hline$E P S O$ & $1 \times 10^{-6}$ & $K_{2}$ & 0.388 \\
\hline$E F M I N$ & 0.01 & $K_{3}$ & 0.298 \\
\hline
\end{tabular}

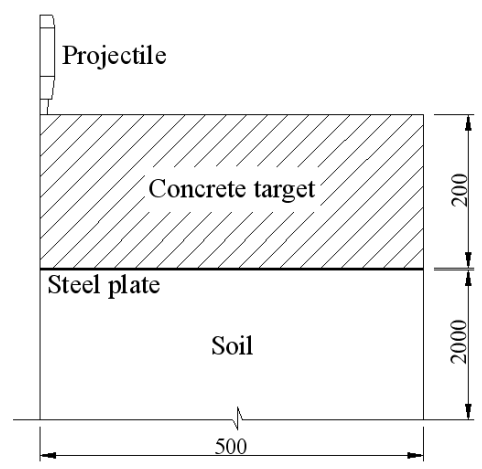

Figure 5: $\quad$ Analytical model (unit: $\mathrm{mm}$ ).

The numerical analytical results of the penetration depth by LS-DYNA software were shown in Table 5. A good agreement between the numerical results and experimental data is observed. It is demonstrated that the penetration of projectile into PFRC targets can be simulated by LS-DYNA based on the JHC model.

\section{Conclusions}

The following conclusions can be made according to the above experimental and numerical investigations.

(1) The value of dynamic compressive strength $\sigma_{d}$ and $\sigma_{d} / \sigma_{\mathrm{s}}$ increase with the increasing of $\dot{\varepsilon}$. However, the addition of excessive fiber may decrease the dynamic compressive strength of PFRC.

(2) PFRC has the same strain-rate sensitive with concrete. In the strain rate range of $10^{1} \mathrm{~s}^{-1}$ and $10^{2} \mathrm{~s}^{-1}$, the value of $\sigma_{d} / \sigma_{\mathrm{s}}$ of PFRC is almost the same as that of 
concrete. Therefore, the data of strain-rate sensitivity of concrete are suggested to adopted when the test data of PFRC are insufficient.

(3) The numerical predictions for the penetration depth agree well with the experimental data. The penetration of projectile into PFRC targets can be simulated by LS-DYNA based on the JHC model. However, The material parameters in the JHC model should be carefully determined based on the relevant test data and the effects of polypropylene fiber reinforcement on the material parameters should be reasonably considered, in order to numerical simulation of penetration of projectile into PFRC targets.

\section{Acknowledgements}

The research presented in this paper was sponsored by the National Science Fund for Distinguished Young Scholars of China.

\section{References}

[1] Xu Zhijun. (2003). Technic and Application of Fiber Reinforced Concrete, China building industry Press (in Chinese).

[2] Manolis G. D., Gareis P. J., Dynamic Properties of Polypropylene FiberReinforced Concrete Slabs. Cement and Concrete Composites, 1997,19:341-349 (in Chinese).

[3] Ma Yi-ping, Tan Mu-hua. Effects of Polypropylene Fibers on the Physical and Mechanical Properties of Cement Based Composites(I). Journal of Building Materials. 2000,3(1):48-52 (in Chinese).

[4] Yao Wu, Ma Yi-ping. Effects of Polypropylene Fibers on the Physical and Mechanical Properties of Cement Based Composites(II). Journal of Building Materials. 2000,3(3):235-239 (in Chinese).

[5] Bischoff P H. Compressive response of concrete to hard impact. Imperial College of Science, Technology and Medicine, 1988.

[6] Bischoff P H, Pery S H. Compressive behavior of concrete at high strain rates. Material and Structure. 1991,144(24):425-450.

[7] Bischoff P H, Pery S H. Impact behavior of plain concrete in uniaxial compression. Journal of Engineering Mechanics, 1995,121(6): 685-693.

[8] Gong Zi-ming, Fang Qin. Numerical simulation of long rod projectile penetrating into thick targets. Journal of PLA Univ. of Sci. \& Tech, 2001,2(4):64-68 (in Chinese).

[9] Holmquist T. J., Johnson G. R., Cook W. H. A Computational Constitutive Model for Concrete Subjected to Large Strains, High Stain Rate and High Pressures. Jackson N, Dickert S. The 14th International Symposium on Ballistics, USA: American Defense Prepareness Association, 1993:591-600.

[10] LS-DYNA Version 970 Keyword User's Manual (2003). Livermore Software Technology Corporation. 